\title{
Data, Social Determinants, and Better Decision-making for Health: the 3-D Commission
}

\author{
Olivia Biermann • Meggie Mwoka • Catherine K. Ettman • Salma M Abdalla • Sherine \\ Shawky • Jane Ambuko • Mark Pearson • Zahra Zeinali • Sandro Galea • Blessing \\ Mberu • Laura Magaña Valladares
}

Accepted: 7 May 2021 / Published online: 19 August 2021

(C) The New York Academy of Medicine 2021

\begin{abstract}
More than a decade after the World Health Organization Commission on the Social Determinants of Health (SDoH), it is becoming widely accepted that social and economic factors, including but not limited to education, energy, income, race, ethnicity, and housing, are important drivers of health in populations. Despite this understanding, in most contexts, social
\end{abstract}

O. Biermann

Department of Global Public Health, Karolinska Institutet, Solna, Sweden

e-mail: olivia.biermann@ki.se

O. Biermann · M. Mwoka • C. K. Ettman - S. M. Abdalla •

S. Shawky · J. Ambuko - M. Pearson - Z. Zeinali · S. Galea •

B. Mberu • L. M. Valladares

Rockefeller Foundation-Boston University 3-D Commission on

Determinants, Data, and Decision-making, Boston, USA

M. Mwoka

e-mail: meggiemwokz@gmail.com

C. K. Ettman

e-mail: cettman@bu.edu

S. Shawky

e-mail: shshawky@aucegypt.edu

J. Ambuko

e-mail: jane.ambuko@uonbi.ac.ke

M. Pearson

e-mail: mark.pearson@oecd.org

Z. Zeinali

e-mail: zzeinal1@alumni.jh.edu

S. Galea

e-mail: sgalea@bu.edu

B. Mberu

e-mail: bmberu@aphrc.org

L. M. Valladares

e-mail: lmagana@aspph.org determinants are not central to local, national, or global decision-making. Greater clarity in conceptualizing social determinants, and more specificity in measuring them, can move us forward towards better incorporating social determinants in decision-making for health. In this paper, first, we summarize the evolution of the social framing of health. Second, we describe how the

\section{K. Ettman \\ Boston University School of Public Health, Boston, USA}

S. M. Abdalla $(\bowtie) \cdot$ S. Galea

Department of Epidemiology, Boston University School of Public Health, Boston, USA

e-mail: abdallas@bu.edu

S. Shawky

The Social Research Center, The American University in Cairo, Cairo, Egypt

\author{
J. Ambuko \\ University of Nairobi, Nairobi, Kenya
}

M. Pearson

OECD, Paris, France

B. Mberu

African Population and Health Research Center, Nairobi, Kenya

L. M. Valladares

Association of Schools and Programs of Public Health (ASPPH), Washington DC, USA 
social determinants are conceptualized and contextualized differently at the global, national, and local levels. With this, we seek to demonstrate the importance of analyzing and understanding $\mathrm{SDoH}$ relative to the contexts in which they are experienced. Third, we problematize the gap in data across contexts on different dimensions of social determinants and describe data that could be curated to better understand the influence of social determinants at the local and national levels. Fourth, we describe the necessity of using data to understand social determinants and inform decisionmaking to improve health. Our overall goal is to provide a path for our collective understanding of the foundational causes of health, facilitated by advances in data access and quality, and realized through improved decision-making.

Keywords Social determinants of health $\cdot \mathrm{SDoH} \cdot \mathrm{Data} \cdot$ Decision-making $\cdot$ Frameworks

\section{Introduction}

Improving decision-making for health requires a comprehensive understanding of what health is, together with an understanding of what influences health across different contexts around the world. A growing understanding of the role of social determinants of health $(\mathrm{SDoH})$ suggests that a full understanding of health requires engagement with a range of social and economic forces, including but not limited to education, energy, income, race, ethnicity, and housing, if we are to create better population health.

Today, increasing amounts of data that can be used to characterize the social determinants are available and have enormous potential to inform decision-making and improve health, well-being, and health equity. Yet, substantial gaps remain in the availability of data across the globe, and the uniformity of data availability across determinants varies. Thus far, there has been little formal effort to consider whether we are using the available data effectively to consider the foundational causes of health [1] and little attention has been paid to the nexus of social determinants, data, and decision-making [2]. In this paper, we (1) summarize the evolution of the social framing of health, (2) contextualize the SDoH, (3) problematize the gap in data on different $\mathrm{SDoH}$ across contexts, and (4) describe the necessity of using data to understand social determinants and inform decisionmaking to improve health.

Social Framing of Health

As our understanding of health evolved throughout the twentieth century, we have come to understand health as being more than the absence of disease, moving towards a notion of health as a complete state of mental and physical well-being. When the World Health Organization (WHO) Constitution was signed in 1946, the WHO stressed that health is a fundamental human right for all [3]. The WHO also called for a shift from focusing on curing diseases towards preserving health through health promotion and prevention of diseases, as well as restoring health through healthcare services. This new direction moved the concept of health from the narrow spectrum of disease and medicine to a broader definition of health as "a state of complete physical, mental and social well-being and not merely the absence of disease or infirmity." [4] The WHO further described well-being as a state in which "an individual realizes his or her own abilities, can cope with the normal stresses of life, can work productively and fruitfully and is able to make a contribution to his or her community." [5]

The United Nations (UN) Universal Declaration of Human Rights and the UN Committee on Economic, Social and Cultural Rights laid further groundwork in defining health. The Universal Declaration of Human Rights [6] pointed to the need for an appropriate standard of living for all to secure the right to health. The Declaration clearly spelled out that in addition to medical care, the sick required food, clothing, housing, employment, and necessary social services. Moreover, the Declaration highlighted that vulnerable groupssuch as the elderly, children, women, people with disabilities, and any other people suffering from hardships - needed particular attention and protection in the realm of health. In 1966, the Committee on Economic, Social and Cultural Rights defined the "Right to Health" [7] as the "enjoyment of a variety of facilities, goods, services and conditions" [7] and shaped health within the wide socio-economic factors that promote the conditions in which people live [7]. The Committee also put responsibility on governments to respect people's right to health and to adopt appropriate legislations, policies, and programs to ensure the realization of the "Right to Health." These efforts made it clear that the production of health lies not only in the 
work of clinical medicine but is rooted in governance and public policies [7].

The new health perspective was revitalized by the landmark WHO and UNICEF international conference in Alma-Ata in 1978. The triumph of the event was the adoption of the Alma-Ata Declaration [8] defining the goal "Health for All by the year 2000," [8] recognizing the need for intersectoral action for health and identifying Primary Health Care as the tool. The Declaration gave prominence to the need for action from many other social and economic sectors in addition to the health sector. In parallel came the Human Development Theory which grew in importance in the 1980s with the work of Amartya Sen and his Human Capabilities perspective that defined human development in terms of long and healthy life, knowledge, and decent standard of living.

The progress in the global health conversation over the past half century encouraged global action towards standard measures to monitor progress in health. This vision was perhaps first tangibly realized through the Millennium Development Goals (MDGs) [9]. The eight MDGs with 21 targets and 60 indicators guided development work, with a focus on reducing poverty, around the world until 2015. The MDG agenda has guided the development efforts starting from the year 2000 to 2015 . Over the 15 years, there were significant achievements made, but many challenges persisted as millions of people still lived in poverty and hunger, without access to basic services; several health conditions persisted with significant health differences between the poor and the rich.

The post-2015 agenda, articulated by the Sustainable Development Goals (SDGs), built on the successes on the MDGs under an animating purpose to "Leave no one behind." [10] The 17 SDGs include 169 targets that span social, environmental, and economic dimensions, and are founded on the principles and values of human rights, social justice, and ethical obligations. Most importantly, the SDG agenda goes beyond a symptomatic approach, focusing on poverty or sickness. Instead, SDGs focus on good governance and public policies that avoid poverty and sickness, that promote education, and that fundamentally encompass the breadth of SDoH.

Even before the SDGs were adopted, there was an increasing academic and practical focus on the social determinants, i.e., the conditions in which people are born, grow, live, work, and age, that ultimately affect health. SDoH are shaped by the distribution of wealth, power, and resources at global, national, and local levels, which are themselves influenced by policy choices [11]. The 2008 WHO Commission on the Social Determinants of Health (CSDH) was an important step forward, an effort to provide evidence and confirm the previous landmarks and concepts linked to health, human rights, and human development [12]. The CSDH reinforced that inequalities in health are determined by the inequalities in various exposures that an individual encounters in their life course [12]. One of the central observations of the CSDH was that in order to eliminate health inequalities (i.e., the uneven distribution of health), health inequities (i.e., avoidable or preventable differences among groups of people) must be reduced. Importantly, the CSDH noted that equity in healthcare is not a proxy for equity in health, and that equity in health is simply unachievable without attention paid to the foundational social determinants that produce health in populations [12].

Building on these concepts, several landmark statements advanced our understanding of SDoH and their incorporation into a new development agenda. In 2010, the Adelaide Statement on "Health in All Policies" pointed out that the interdependence of public policy requires not only an integrated response across government departments, but partnerships with the business sector and civil society [13]. In 2011, the World Conference on SDoH in Rio de Janeiro [14] called for increased engagement of all sectors. The Rio Political Declaration considered how intersectoral action and structures could reduce health inequalities by tackling the SDoH. The United Nations General Assembly report in 2011 on the prevention and control of noncommunicable diseases emphasized the need for "Health in All Policies" approaches, and the WHO identified the intersectoral action as a key driver and strategy in achieving universal health coverage [15].

\section{Conceptualizing and Contextualizing the Social Determinants of Health}

\section{Existing Frameworks}

A wide variety of frameworks that conceptualize the SDoH exist (Appendix). In past years, the conceptual framework created by the WHO CSDH has been widely used and adapted by a range of actors [12]. The CSDH framework considers health in its broad definition and 
illustrates pathways through which SDoH affect health outcomes and their distribution across various social strata. In the framework, the concept of SDoH covers the full set of social conditions in which people are born, grow, live, work, and age, including the healthcare system. These are the contextual forces referred to as intermediate determinants. The framework highlights how pervasive and persisting health inequalities can be linked to the unequal distribution of these conditions, which are the product of the wider social, economic, political, environmental, and cultural systems and structures. Such systems and structures are referred to as the structural determinants, or the causes of causes.

Other SDoH frameworks, published in the past decade, frequently and explicitly include two additional important intermediate determinants: community and housing. Housing and community have long been highlighted as central to social determinants, appearing in one of the first SDoH frameworks [16]. Elements of community functioning that influence health include social capital, connectedness, and capacity [17]; support systems and community engagement [18]; experience of class, racism, and immigration [19]; and discrimination and incarceration [20]. Danaher [17] emphasizes that the better a community works, the more resilient it is, and the better it can mediate the impact of health inequities. Furthermore, housing as an SDoH includes the full range of exposures that inform where we live, including neighborhood conditions, safety, parks, transportation, playgrounds, walkability, and zip code [18]; access to foods that support healthy eating patterns, crime and violence, environmental conditions, and quality of housing [20,21]; and residential segregation and exposure to toxins [19]. Moreover, in conceptualizing $\mathrm{SDoH}$, others have put an emphasis on the life-course perspective of the social determinants such as Kaplan and colleagues [22], or included elements like power structures [23] and a range of determinants that have been considered moral [24] or emotional [25] determinants of health.

Finally, there are several frameworks that integrate healthcare systems into $\mathrm{SDoH}$ frameworks including frameworks that define the healthcare system, e.g., the WHO building blocks [26], the control knobs framework [27], and the WHO health systems strengthening (WHO-HSS) framework [28]. The latter provides the preferred and alternative data sources for each block of indicators for different time horizons. The framework also outlines what is needed across the results chain in terms of tools for data quality assurance, synthesis, and analysis, with a focus on building country level capacity. The framework also addresses the importance of dissemination, communication, and use of the monitoring and evaluation results to inform policymaking at all levels.

\section{Context Matters}

The CSDH framework, the WHO-HSS framework, and other subsequent frameworks provide a good starting point from which to consider the social, structural, and intermediate determinants of health $[12,28]$. These frameworks highlight the centrality of these determinants to the production of health globally. However, it is important to note that while core determinants of health may be universal, the urgency and prioritization of certain determinants may vary depending on a country's context, across global, national and local levels, and based on the ability of data production and use. SDoH can and should be contextualized, and this is being increasingly recognized in the global SDoH conversation. Three examples illustrate this point.

First, depending on income level, countries may tackle a specific health determinant, such as housing, in various ways. Housing is an intermediate determinant of health that influences and is influenced by root causes, such as social, macroeconomic, and public policies, as well as the social position such as education, income, and ethnicity/race [12]. Health and well-being are influenced by the physical structure and design of the house itself, the social and psychological aspects of the home, the social characteristics and range of services of the community, and the neighborhood [29]. The contextual differences in the housing policies and strategies, as well as the differential impact of housing on health, may result in different countries considering action on housing quite differently. For example, Japan may focus on energy-efficiency [30, 31] as a core approach to improving the relation of housing to health, while Kenya, as part of the government's "Big Four" agenda, may prioritize facilitating affordable housing [32].

Second, different determinants may take different priorities to address a given health need in a country. For example, approaches to tuberculosis (TB) may be prioritized across global, national, and local levels. Globally, the focus may be on creating a socioeconomic and political context conducive to TB control [33]. 
Nationally, countries may concentrate on providing social protection to TB patients to mitigate catastrophic costs [34]. At the same time, locally, the target may be to fight social stigma against the disease [35].

Third, the prioritization of certain determinants may vary based on the availability and use of data. For instance, Rashid and colleagues [36] highlighted the importance of capturing the experiences of people living and working in slums in Bangladesh during the COVID-19 pandemic and translating those to contextspecific strategies for lockdown to avoid starvation of many. By way of another example, in the context of TB, data gaps, caused by lack of funding to sustain comprehensive data collection efforts, have informed the allocation of resources, and the assessment of whether increases in expenditures are leading to improvements in program performance [37].

The contextual specificity of SDoH, coupled with a growing recognition of the centrality of these same $\mathrm{SDoH}$ to health production worldwide, militates for the emergence of data that can better understand SDoH to the end of informing decision-making.

\section{Operationalizing Frameworks}

The operationalization of SDoH frameworks requires choosing health-related indicators that reflect their health impact and the intermediate determinants that mediate this impact. According to the CSDH and the WHO-HSS frameworks, the list of indicators can be classified into health impact indicators, health-related risk factors (outcomes), and healthcare system determinants. In addition, to reflect the social dimensions of illhealth and guide policies to improve health, social stratifications (stratifiers) must be identified that are sensitive to capturing health inequalities. Such stratifiers include gender, income, wealth, educational level, occupational status, race, ethnicity, migratory status, and place of residence. Each country needs to identify the particular groupings that reflect social stratification that are amenable to change through structural reforms. Furthermore, inequities in health can be observed from the existence of systematic inequalities in health distribution; however, there is no consensus on a standard measure. There are numerous measures to quantify inequalities in health [38-45]. Previous research has also compared the various inequality measures [46] and applied them in data analyses across five countries [47, 48].

\section{Data Gaps across Contexts on Different Dimensions of the Social Determinants of Health}

There are substantial global data gaps across contexts and on different dimensions of the SDoH. Data on the SDoH vary in availability (e.g., in low-income settings), ownership (e.g., public versus private), comprehensiveness of sources (e.g., insufficient population-based sources such as vital registration, census, and surveys), types (e.g., qualitative and quantitative), and levels of data (e.g., national and local). Data on SDoH outside the health sector (e.g., housing) may be available, but are often inaccessible to health authorities due to siloed governance and data ownership. Notably, even if data are available, there are often no national regulations to ensure data sharing, no lists of priority social stratifiers relevant to each country, no distributional inequality measure to monitor magnitude, and no correct interpretations of results to guide decision-makers. Populationbased information is the means to correctly understand the national reality and measure the impact of policies and strategies, while such information is still limited in many low- and middle-income countries. Moreover, many observatories, platform databases, and dashboards provide a substantial amount of data, e.g., the World Bank, WHO, and World Development Indicators. Yet, these data sources mostly provide overall national averages or measure health inequalities using absolute of relative differences in numbers, proportions, and rates. Such measures do not always reflect the distributional inequalities.

This paucity of data often results in data presentation that elides our understanding of health determinants and the needs of populations, particularly among vulnerable groups. For example, while the size of slum populations in Sub-Saharan Africa doubled between 1990 and 2016, there are real limitations to the enumeration of these informal urban settlements in census data and national surveys [49]. As such, this lack of data limits our understanding of what determines slum dwellers' health and well-being. The lack of data across African cities has further hindered the answer to questions critical to the health needs of the urban poor, and that can guide urban health programming by implementing agencies and local governments $[50,51]$.

Offsetting these limitations are growing investments in data collection and analyses at local levels all over the world that have started to provide windows into a better 
understanding of SDoH across several cities that can be adapted and adopted to inform policy and action across the region [52]. Building on data across low-income communities and securing political support for policy and action will be paramount to improving urban health generally, including in informal settlements. Example 1 highlights how data gaps on the SDoH have been filled in Kenya, while Example 2 provides insights from Bangladesh. Example 3 points out Singapore as a data rich and information rich setting.

Example 1: Filling Data Gaps on Social Determinants of Health in Kenya

In Nairobi, Kenya, investments in local data collection and analysis have begun to fill critical gaps in recent years $[50,53]$. Data can now offer insights into the health and well-being of populations and individuals in different social positions. For example, data are now available on slum population's disease burden and excess mortality, as well as access to healthcare, family planning, and public sector services. Moreover, there are now data on intermediate determinants such as housing conditions and availability of water and sanitation, and structural determinants including livelihood opportunities [50,53]. These insights provided impetus for action to address some of the health determinants and led to significant impact [52]. At the same time, determinants could be identified where little or no action had so far been taken, such as the physical environment including indoor and outdoor pollution [52].

Example 2: Filling Data Gaps on Social Determinants of Health in Bangladesh

In Bangladesh, data for slum areas, non-slum areas, and other urban areas exist, e.g., on fertility and family planning, maternal and newborn health, childhood mortality, and health service utilization. In addition, data are available on structural determinants such as socioeconomic status, education, and migration, as well as intermediary determinants such as household characteristics [54, 55]. However, existing household survey methods are still inadequate, and gaps remain in representing the urban population and addressing health inequities [56]. Two entities of the Government of Bangladesh (the Bangladesh Bureau of Statistics and the General Economics Division) are trying to fill in the data gaps with respect to different
Sustainable Development Goal indicators. The BRAC James P. Grant School of Public Health is also contributing to fill in the data gap. In the past 5 years, the BRAC James P. Grant School of Public Health conducted at least 11 research studies in different slums of Bangladesh. These studies generated data on structural determinants (e.g., the socioeconomic context and livelihood aspects) and intermediate determinants (e.g., neighborhood) of slum dwellers that impact good health and well-being.

Example 3: Rich Data on Social Determinants of Health in Singapore

Available data in Singapore show that $90.4 \%$ of the country's inhabitants are homeowners [57]. Furthermore, data can provide insights into how homeownership affects people's health, e.g., comparisons of health-related quality of life between rental and owner-occupied neighbourhoods demonstrated that staying in rental neighbourhoods was associated with more mental health problems [58]. Another study revealed that people staying in public housing were more likely to be male, require financial assistance, have chronic obstructive pulmonary disease, and use antidepressants and anti-psychotic medications [59]. Such insights are crucial to inform decision-making for better health. Moreover, the Housing \& Development Board in Singapore signed two research and development agreements with the Nanyang Technological University and the Singapore University of Technology and Design in 2017 to further leverage the power of data by guiding planners and architects in creating new housing solutions in line with residents' evolving needs and aspirations [60].

\section{Using Data to Understand the Social Determinants of Health and Inform Decision-making}

While there is little question, to our mind, that better data are needed to inform decision-making around the $\mathrm{SDoH}$, ultimately, actionable information from data requires the engagement of people with data, understanding data needs, and interpreting these data appropriately [61]. Exchange with and among stakeholders has been described as the key influencing factor for evidenceinformed decision-making [62]. In particular, communicating insights learned from data represents a core 
function of data translation that stands to influence decision-making. One example of communicating data to decision-makers, as well as the concerned public, is James Cheshire's work on mapping life expectancy along the London underground network [63]. The analogy of changing life expectancy along individual underground tube lines has helped communicate life expectancy data, raising awareness about health inequities. Another example of communicating data is the Gapminder Foundation, co-founded by the late Hans Rosling. Using data from sources such as the Institute for Health Metrics and Evaluation and the United Nations, Gapminder offers graphs that visualize the relation between health determinants and health outcomes, e.g., income and life expectancy at birth. Other determinants that can be explored through Gapminder are related to economy, education, energy, environment, infrastructure, society, and work [64]. In addition, the USbased organization Opportunity for Health communicates data on how economic opportunity - the "American Dream"- affects America's health, and identifies ways to help bolster both economic opportunity and health [65]. The examples showcase the power of leveraging data and making connections about the relation between social determinants and health outcomes.

While communicating data is a first step, challenges often remain around using data to inform decision-making. Health indicators are often influenced by a variety of interconnected SDoH, such as the ones displayed in the CSDH framework, making data use for decision-making complex. For example, obesity is influenced by food supply, material security, environments conducive of physical activity, and supportive social networks [66]. At the same time, a person with a lower socioeconomic status is more likely to live in an area with a limited supply of healthy food and few options for physical activity, which influence obesity negatively. Addressing $\mathrm{SDoH}$ therefore requires integrated and intersectoral approaches, e.g., regulating food advertising and designing urban environments conducive of health [66], as well as school interventions, nutrition policies, and taxes on sugary drinks [67]. The example of obesity also highlights the need to consider additional determinants of health in the CSDH framework such as politics, commercial interests [68], emotions, culture, and religion, as well as health outcomes such as mental and emotional health.
The UK and Singapore offer interesting examples of approaches to tackling obesity and promoting health lifestyles informed by a broad set of data, including social determinants data. In the UK, the Foresight project applied a holistic approach and mapped determinants of obesity and then proposed implementation techniques from national to local levels [69]. In response to the growing body of evidence, including from the Foresight project, decision-makers commissioned the whole systems approach to obesity program - a "Health in All Policies" approach [70]. In Singapore, the government's Health Promotion Board has partnered with Fitbit in piloting the Insights Singapore initiative to promote healthy lifestyles [71]. Fitbit is an American consumer electronics and fitness company, best known for a smart watch that is able to track a person's activity, exercise, food, weight, and sleep. The initiative uses the Fitbit smart watch to understand the health behavior and lifestyles of Singaporeans with the aim of helping them get healthier through meaningful and sustained behavior change and continued development of health promotion policies and programs.

\section{Conclusion}

There is immense potential for data to inform our understanding of social determinants to the end of better decision-making for health. We suggest that there are several key directions in which the field can productively grow. First, policies for health should be founded on a comprehensive conceptualization of SDoH. Beyond the WHO CSDH framework, conceptualizations of $\mathrm{SDoH}$ must become more comprehensive and actionable by reflecting the contextual nature of SDoH. Second, data gaps must be filled through complete and comprehensive data sources which are currently lacking or out-ofdate. This would allow for a more complete understanding of SDoH in a given context, the needs of vulnerable populations and existing inequities. A more complete understanding, in turn, offers major opportunities for informing policy and practice, and to increase accountability. A human rights-based approach to data will ensure the use of data is consistent with international human rights norms and principles, including for participation, self- 
identification, transparency, privacy, and accountability [72]. Third, data use is challenged by the complexity and interconnectedness of SDoH, calling for integrated and intersectoral approaches to tackle health outcomes. Data collection and disaggregation must go beyond gender, geography, and age, ensuring that all health determinants are identified and addressed [72], to leave no one behind [73].

\section{Appendix. Relevant social determinants of health frameworks}

1. Bay Area Regional Health Inequities Initiative (BARHII). The BARHII framework. Updated 2020. https://www.barhii.org/barhii-framework

2. Centers for Disease Control and Prevention (CDC). Health impact in 5 years. Updated 2018. https://www.cdc.gov/policy/hst/hi5/index.html

3. Dahlgren G, Whitehead M. Policies and strategies to promote social equity in health. Institute for Futures Studies; 1991. https://core.ac. uk/download/pdf/6472456.pdf

4. Health in all policies: prospects and potentials. European Observatory on Health Systems and Policies; Ministry of Social Affairs and Health Finland; 2006. https://www.euro.who. int/en/health-topics/health-determinants/socialdeterminants/publications/pre-2007/health-in-allpolicies-prospects-and-potentials-2006

5. Evans RG, Stoddart GL. Producing health, consuming health care. Soc Sci Med. 1990;31(12):13471363. doi:10.1016/0277-9536(90)90074-3. https:/www.sciencedirect.com/science/article/abs/ pii/0277953690900743?via\%3Dihub

6. Cooperative Extension's National Framework for Health and Wellness.; 2014. https://www.aplu. org/members/commissions/food-environment-andrenewable-resources/CFERR_Library/nationalframework-for-health-and-wellness

7. Kaplan GA, Everson SA, Lynch JW. The contribution of social and behavioral research to an understanding of the distribution of disease: a multilevel approach. In: Smedley BD, Syme SL, eds. Institute of Medicine (US) Committee on Capitalizing on Social Science and Behavioral Research to Improve the Public's Health. National Acade- mies Press (US); 2000. https://www.ncbi.nlm.nih. gov/books/NBK222836/

8. Annis R, Beattie M, Racher FF. Rural community health and well-being: a guide to action.; 2004. https://www.brandonu.ca/rdi/publication/ruralcommunity-health-and-well-being-a-guide-to-action/

9. Artiga S, Hinton E. Beyond health care: the role of social determinants in promoting health and health equity.; 2018. https://www.kff.org/disparitiespolicy/issue-brief/beyond-health-care-the-role-ofsocial-determinants-in-promoting-health-andhealth-equity/

10. Secretary's Advisory Committee on Health Promotion and Disease Prevention Objectives for 2020. Healthy People 2020: an opportunity to address the societal determinants of health in the United States. Published 2010. http://www.healthypeople.gov/2010 /hp2020/advisory/SocietalDeterminantsHealth.htm

11. Danaher A. Reducing disparities and improving population health: the role of a vibrant community sector. Wellesley Institute. Published 2011. https://www. wellesleyinstitute.com/publications/reducingdisparities-and-improving-population-health-the-roleof-a-vibrant-community-sector/

12. Frieden TR. A framework for public health action: the health impact pyramid. Am J Public Health. $2010 ; 100(4): 590-595$. doi:10.2105/ AJPH.2009.185652. https://www.ncbi.nlm.nih. gov/pmc/articles/PMC2836340/

13. Brennan RL, Baker E, Metzler M. Promoting health equity a resource to help communities address social determinants of health. U.S. Department of Health and Human Services, Centers for Disease Control and Prevention; 2008. https://www.cdc.gov/nccdphp/dch/programs/ healthycommunitiesprogram/tools/pdf/sdohworkbook.pdf

14. Commission on Social Determinants of Health (CSDH). Closing the gap in a generation: health equity through action on the social determinants of health.; 2008. https://www.who.int/publications/i/item/WHOIER-CSDH-08.1

Acknowledgements We thank Leona Ofei for her support formatting this paper. The Rockefeller Foundation-Boston University 3-D Commission (Grant number: 2019 HTH 024). 


\section{References}

1. Keyes K, Galea S. What matters most: quantifying an epidemiology of consequence. Ann Epidemiol. 2015;25(5): 305-11. https://doi.org/10.1016/j.annepidem.2015.01.016.

2. Galea S, Abdalla SM, Sturchio JL. Social determinants of health, data science, and decision-making: forging a transdisciplinary synthesis. PLoS Med. 2020;17(6):e1003174undefined. https://doi.org/10.1371/journal.pmed.1003174.

3. United Nations (UN). UN General Assembly, entry into force of the Constitution of the World Health Organization, 17 November 1947, A/RES/131.; 1947. Accessed 16 May 2021. https://www.refworld.org/docid/3 b00f09554.html.

4. World Health Organization (WHO). Preamble to the constitution of WHO as adopted by the international health conference, New York, 19 June - 22 July 1946; signed on 22 July 1946 by the representatives of 61 states (official records of WHO, no. 2, p. 100) and entered into force on 7 April 1948, Geneva; 1948.

5. World Health Organization (WHO). Promoting mental health: concepts, emerging evidence, practice (Summary Report), Geneva; 2004.

6. United Nations(UN). United Nations universal declaration of human rights 1948, New York, NY; 1948.

7. United Nations (UN). UN General Assembly, International Covenant on Economic, Social, and Cultural Rights (ICESCR) (Dec 16, 1966, Entered into Force Jan 3, 1976); 1966. Accessed October 27, 2020. https://www.refworld. $\mathrm{org} /$ cgi-bin/texis/vtx/rwmain?docid=3ae6b36c0

8. World Health Organization (WHO). Declaration of Alma Ata: international conference on primary health care, Alma Ata, USSR, 6-12 September 1978; Geneva. 1978.

9. United Nations (UN). Millennium Development Goals; 2010. Accessed October 28, 2020. https://www.un. org/millenniumgoals/

10. United Nations (UN). Sustainable Development Goals; 2015. Accessed October 28, 2020. https://sdgs.un.org/goals

11. World Health Organization (WHO). Social determinants of health. Accessed September 22, 2020. http://www.who. int/social determinants/en/

12. Commission on Social Determinants of Health (CSDH). Closing the gap in a generation: health equity through action on the social determinants of health. Geneva; 2008.

13. World Health Organization (WHO) Government of South Australia. Adelaide statement on health in all policies: moving towards a shared governance for health and well-being. Report from the international meeting on health in all policies, Geneva; 2010.

14. World Health Organization (WHO). World conference on social determinants of health: meeting report. In: World Conference on Social Determinants of Health, Rio de Janeiro, 19-21 October 2011; Geneva. 2011.

15. United Nations General Assembly. Prevention and control of noncommunicable diseases, report of the secretary general. New York, NY; 2011.

16. Dahlgren G, Whitehead M. Policies and strategies to promote social equity in health. Background document to WHO - strategy paper for Europe. Institute for Future Studies, Stockholm; 1991.
17. Danaher A. Reducing disparities and improving population health: the role of a vibrant community sector. Wellesley Institute. Published 2011. Accessed 16 May 2021. https://www.wellesleyinstitute.com/publications/reducingdisparities-and-improving-population-health-the-role-of-avibrant-community-sector/

18. Artiga S, Hinton E. Beyond health care: the role of social determinants in promoting health and health equity; 2018. Accessed 16 May 2021. https://www.kff.org/racial-equityand-health-policy/issue-brief/beyond-health-care-the-roleof-social-determinants-in-promoting-health-and-healthequity/.

19. Bay Area Regional Health Inequities Initiative (BARHII). The BARHII framework. Updated 2020. https://www. barhii.org/barhii-framework

20. Secretary's Advisory Committee on Health Promotion and Disease Prevention Objectives for 2020. Healthy People 2020: an opportunity to address the societal determinants of health in the United States. Published July 26, 2010. http://www.healthypeople.gov/2010/hp2020 /advisory/SocietalDeterminantsHealth.htm

21. Mberu B, Mutua M, Kabaria C, Amugsi D, Muindi K. Levels of household exposure to solid waste dumpsites and associated loss to health in urban Kenya and Senegal. Cities Health. 2020:1-12. https://doi.org/10.1080 /23748834.2020.1768686.

22. Kaplan GA, Everson SA, Lynch JW. The contribution of social and behavioral research to an understanding of the distribution of disease: a multilevel approach. In: Smedley BD, Syme SL (eds) Promoting health: intervention strategies from social and Behavioral research. National Academies Press, Washington DC; 2000.

23. Chapman AR. The social determinants of health, health equity, and human rights. Health Hum Rights. 2010;12(2): 17-30. https://doi.org/10.1017/cbo9781316104576.007.

24. Berwick DM. The moral determinants of health. JAMA - J Am Med Assoc. 2020;324(3):225-6. https://doi.org/10.1001 /jama.2020.11129.

25. Larson H, Simas C, Horton R. The emotional determinants of health: the Lancet-London School of Hygiene \& Tropical Medicine Commission. Lancet. 2020;395(10226):768-9. https://doi.org/10.1016/S0140-6736(20)30050-7.

26. World Health Organization (WHO). Systems thinking for health systems strengthening, Geneva; 2009a.

27. Roberts M, Hsiao W, Berman P, Reich M. Getting health reform right: a guide to improving performance and equity. Oxford University Press, New York, NY; 2008

28. World Health Organization (WHO). Monitoring and evaluation of health systems strengthening: an operational framework, Geneva; 2009b.

29. Fuller-Thomson E, Hulchanski JD, Hwang S. The housing/ health relationship: what do we know? Rev Environ Health. 2000;15(1-2):109-33. https://doi.org/10.1515 /REVEH.2000.15.1-2.109.

30. Smith C. Shrinking the footprint of Japan's building sector . our world . Published 2008. Accessed August 6, 2020. https://ourworld.unu.edu/en/greening-a-giant

31. Kobayashi M. The housing market and housing policies in Japan; 2016. Accessed November 2, 2020. https://www. adb.org/publications/housing-market-and-housing-policiesjapan. 
32. Government of Kenya. Kenya Affordable Housing Programme Development Framework Guidelines; 2018. Accessed November 2, 2020. https://www. housingandurban.go.ke/wp-content/uploads/2018/11 /Development-Framework-Guidelines-Release-Version.pdf

33. World Health Organization. World tuberculosis report, Geneva; 2020. Accessed 16 May 2021. Link: https://apps. who.int/iris/bitstream/handle/10665/336069 /9789240013131-eng.pdf.

34. Bhargava A, Bhargava M, Juneja A. Social determinants of tuberculosis: context, framework, and the way forward to ending TB in India. Expert Rev Respir Med. 2020:1-17. https://doi.org/10.1080/17476348.2021.1832469.

35. Craig GM, Daftary A, Engel N, O’Driscoll S, Ioannaki A. Tuberculosis stigma as a social determinant of health: a systematic mapping review of research in low incidence countries. Int J Infect Dis. 2017;56:90-100. https://doi. org/10.1016/j.ijid.2016.10.011.

36. Rashid SF, Theobald S, Ozano K. Towards a socially just model: balancing hunger and response to the COVID-19 pandemic in Bangladesh. BMJ Glob Health. 2020;5: e002715-undefined. https://doi.org/10.1136/bmjgh-2020002715.

37. Floyd K, Pantoja A, Dye C. Financing tuberculosis control: the role of a global financial monitoring system. Bull World Health Organ. 2007;85(5):334-40. https://doi.org/10.2471 /BLT.06.034942.

38. Wagstaff A, Paci P, van Doorslaer E. On the measurement of inequalities in health. Soc Sci Med. 1991;33(5):545-57. https://doi.org/10.1016/0277-9536(91)90212-U.

39. Braveman P. Health disparities and health equity: concepts and measurement. Annu Rev Public Health. 2006;27:167-94. https://doi.org/10.1146/annurev.publhealth.27.021405.102103.

40. Ontario Agency for Health Protection and Promotion (Public Health Ontario). Summary measures of socioeconomic inequalities in health, Toronto, ON; 2013.

41. O’Donnell O, van Doorslaer E, Wagstaff A, Lindelow M. Analyzing health equity using household survey data: a guide to techniques and their implementation, Washington, DC; 2008.

42. Pampalon R, Hamel D, Gamache P. A comparison of individual and area-based socio-economic data for monitoring social inequalities in health. Health Rep. 2009;20(4):85-94.

43. Spinakis A, Anastasiou G, Panousis V, Spiliopoulos K, Palaiologou S, Yfantopoulos J. Expert review and proposals for measurement of health inequalities in the European Union - summary report, Luxembourg; 2011.

44. Chee G, Pielemeier N, Lion A, Connor C. Why differentiating between health system support and health system strengthening is needed. Int $J$ Health Plann Manag. 2013;28(1):85-94. https://doi.org/10.1002/hpm.2122.

45. Koolman X, van Doorslaer E. On the interpretation of a concentration index of inequality. Health Econ. 2004;13: 649-56. https://doi.org/10.1002/hec.884.

46. Shawky S. Measuring geographic and wealth inequalities in health distribution as tools for identifying priority health inequalities and the underprivileged populations. Glob $A d v$ Health Med. 2018;7:1-10. https://doi.org/10.1177 12164956118791955.

47. Shawky S, Rashad H, Khadr Z. Reproductive health inequalities in Egypt: evidence for guiding policies; 2019.
https://documents.aucegypt.edu/Docs/src/Reproductive\%20 Health\%20Inequalities\%20in\%20Egypt.pdf

48. Rashad H, Shawky S, Khadr Z, Afifi M, Sahbani S. Reproductive health equity in the Arab region: fairness and social success; 2019. Accessed December 9, 2020. https://documents.aucegypt.edu/Docs/src/ReproductiveHealth-\%20Equity-in-the-Arab-Region.pdf

49. Mberu BU, Haregu TN, Kyobutungi C, Ezeh AC. Health and health-related indicators in slum, rural, and urban communities: a comparative analysis. Glob Health Action. 2016;9(1):33163.-undefined. doi:10.3402/GHA.V9.33163

50. Center. Population and health dynamics in Nairobi's informal settlements: report of the Nairobi cross sectional slums survey (NCSS) 2012, Nairobi; 2014.

51. Satterthwaite D. Health in urban slums depends on better local data. Paper presented at: The International Conference on Urban Health in Manchester, United Kingdom, 5-7 March, 2014.

52. Ezeh A, Mberu B. Case studies in urban health: Nairobi Kenya. In: Galea S, Ettman CK, Vlahov D (eds) Urban health. Oxford University Press, New York, NY, pp 330 339. 2019.

53. African Population and Health Research Center. Population and health dynamics in Nairobi's informal settlements.; 2002. https://aphrc.org/wp-content/uploads/2018/11 /Report-The-Nairobi-Cross-sectional-Slums-Survey-NCSS2000-1.pdf

54. National Institute of Population Research and Training (NIPORT), MEASURE Evaluation, International Centre for Diarrhoeal Disease Research, Bangladesh (ICDDR,B), Associates for Community and Population Research (ACPR). 2006 Bangladesh urban health survey.; 2008.

55. National Institute of Population Research and Training (NIPORT), International Centre for Diarrhoeal Disease Research, Bangladesh (ICDDR,B), MEASURE Evaluation. Bangladesh urban health survey 2013 Final Report.; 2015.

56. Elsey H, Poudel AN, Ensor T, et al. Improving household surveys and use of data to address health inequities in three Asian cities: protocol for the Surveys for Urban Equity (SUE) mixed methods and feasibility study. BMJ Open. 2018;8(11) https://doi.org/10.1136/bmjopen-2018-024182.

57. Department of Statistics Singapore. Households - latest data. Accessed November 18, 2020. https://www.singstat.gov. sg/find-data/search-by-theme/households/households/latestdata

58. Wee LE, Daniel P, Sim A, Lee R, Tay SM, Luo N, et al. Health-related quality of life in a low-socioeconomic status public rental-flat population in Singapore. Appl Res Qual Life. 2018;13(1):179-95. https://doi.org/10.1007/s11482017-9519-6.

59. Low LL, Wah W, Ng MJ, Tan SY, Liu N, Lee KH. Housing as a social determinant of health in Singapore and its association with readmission risk and increased utilization of hospital services. Front Public Health. 2016; https://doi. org/10.3389/fpubh.2016.00109.

60. OpenGov. HDB Singapore partners with local universities to leverage big data and smart technology in planning, designing and building public housing . Published 2017. Accessed October 1, 2020. https://opengovasia.com/hdb-singaporepartners-with-local-universities-to-leverage-big-data-and- 
smart-technology-in-planning-designing-and-buildingpublic-housing/

61. Lavis J. Assessing country-level efforts to link research to action. Bull World Health Organ. 2006;84(8):620-8. https://doi.org/10.2471/BLT.06.030312.

62. Oliver K, Innvar S, Lorenc T, Woodman J, Thomas J. A systematic review of barriers to and facilitators of the use of evidence by policymakers. BMC Health Serv Res. 2014;14 https://doi.org/10.1186/1472-6963-14-2.

63. Cheshire J. Featured graphic. lives on the line: mapping life expectancy along the London Tube network. Environ Plan A. 2012;44(7):1525-8. https://doi.org/10.1068/a45341.

64. Gapminder Foundation. Tools. Accessed September 28, 2020. https://www.gapminder.org/tools/

65. Opportunity for Health. Accessed October 28, 2020. https://opportunityforhealth.org

66. Friel S, Chopra M, Satcher D. Unequal weight: equity oriented policy responses to the global obesity epidemic. $\mathrm{Br}$ Med J. 2007;335:1241-3. https://doi.org/10.1136 /bmj.39377.622882.47.

67. EVIPNet Europe. Reducing the consumption of sugarsweetened beverages and their negative health impact in Estonia, Copenhagen; 2017.

68. Kickbusch I, Allen L, Franz C. The commercial determinants of health. Lancet Glob Health. 2016;4(12):e895-6. https://doi.org/10.1016/S2214-109X(16)30217-0.
69. Government Office for Science. Foresight tackling obesities: future choices - obesity system atlas.; 2007. Accessed October 28, 2020. https://assets.publishing.service.gov. uk/government/uploads/system/uploads/attachment data/file/295153/07-1177-obesity-system-atlas.pdf

70. Public Health England. Whole systems approach to obesity a guide to support local approaches to promoting a healthy weight; 2019.Accessed October 28, 2020. https://assets.publishing. service.gov.uk/government/uploads/system/uploads/attachment data/file/820783/Whole_systems_approach_to_obesity_guide. pdf

71. Health Insights Singapore (hiSG): working adults. Accessed November 4, 2020. https://www.hpb.gov.sg/hisg/adults

72. OHCHR. A human rights-based approach to data. Leaving no one behind in the 2030 agenda for sustainable development. United Nations Human Rights Office of the High Commissioner, Geneva; 2018.

73. United Nations (UN). United Nations sustainable development cooperation framework guidance, New York, NY; 2019.

Publisher's Note Springer Nature remains neutral with regard to jurisdictional claims in published maps and institutional affiliations. 